RESEARCH REPORT

\title{
Tobacco control policies and smoking in a population of low education women, 1992-2002
}

\author{
David T Levy, Elizabeth A Mumford, Christine Compton
}

J Epidemiol Community Health 2006;60(Suppl II):ii20-ii26. doi: 10.1136/jech.2005.045542

\begin{abstract}
See end of article for authors' affiliations .....................

Correspondence to: Professor D T Levy, Institute for Research and Evaluation, 11710 Beltsville DR, Calverton MD 20705, USA; levy@ pire.org
\end{abstract}

Accepted for publication 10 June 2006

\begin{abstract}
Study objective: To examine recent trends and the role of tobacco control policies associated with smoking among women of low socioeconomic status.

Design: Using four waves of the nationally representative tobacco use supplement to the current population survey (TUS-CPS)-(1992-2002), the study examined trends and used multivariate logistic models of smoking prevalence among low education women to examine the role of cigarette prices, clean air regulations, and tobacco control media campaigns, while controlling for other personal characteristics. Setting: USA.

Participants: Women ages 18 and older who report not having completed high school, compared with other women with greater educational attainment and men ages 18 and older with less than a high school degree.

Main results: Smoking among low education women declined at a greater rate over the study period than among more highly educated women, in contrast with trends of earlier periods. Low education women were found to be particularly responsive to media messages as well as price, especially in comparison with high education women.

Conclusions: The relation between health and socioeconomic status is not immutable; selected tobacco control policies, such as tax increases and media campaigns targeting low education women, may make inroads in reducing the smoking prevalence of this population.
\end{abstract}

California, Massachusetts, and Arizona, have seen particularly large reductions in smoking rates. ${ }^{18}$ However, smoking rates are high among low SES and particular racial/ethnic groups. ${ }^{15}$ Increasingly, the focus of national and state programmes has been on how to target particular sociodemographic groups. ${ }^{21} 22$

A limited number of studies have considered how taxes or clean air policies have affected particular sociodemographic groups. For example, some studies have found that men and women respond differently to price changes, although others have failed to find gender differences. ${ }^{14} 2324$ Townsend ${ }^{25}$ and the US Centers for Disease Control and Prevention (CDC $)^{15}$ found greater price responsiveness in low income populations. $\mathrm{CDC}^{15}$ also has reported that black people and Latinos were more price sensitive than other ethnic groups. Policies such as bans on smoking in the workplace might be expected to have a differential impact on both women and lower SES people, because of lower work participation rates. Ohsfeldt $e t$ $a^{26}$ found less prominent effects on women, and Farrelly et $a l^{27}$ found smaller reductions in smoking rates among low income people. Besides price and work restrictions, the effect on different sociodemographic groups of media/comprehensive campaigns and other policies has not been systematically studied. In particular, studies have focused on either taxes or clear air restrictions, and none has considered the simultaneous implementation of those policies with media campaigns.

Although studies of female smoking have examined SES and some studies of tobacco control policies have looked at the impact on women and those of lower SES, further study is needed, especially regarding women and low SES in conjunction. This paper is intended to begin to fill those gaps. Using a 10 year span of nationally representative data, we examine the role of tobacco control policies associated with smoking among women of low SES. We describe the prevalence of smoking in the selected population, comparing such as price increases, media campaigns, and clean air laws. ${ }^{19}$ States with active tobacco control policies, such as

whw jech.com 
these data to three reference groups-women of two different higher SES groups and men of low SES-and we assess whether tobacco control policies have a differential effect on the selected population compared with the three reference groups. These analyses are intended to inform more precise policy formulation to target the high rate of smoking among low SES women.

\section{METHODS}

\section{Individual level dato}

Four waves of the tobacco use supplement to the current population survey (TUS-CPS)—1992/93, 1995/96, 1998/99, and 2001-02, each with three sample months (usually September, January, and May, except in 2001-02)-were analysed in this study. The probability sample for each wave was based on stratified clusters of households drawn from an initial sampling frame that covers the civilian non-institutionalised population ages 15 and older. The TUS-CPS collects data on individual tobacco use, attitudes toward smoking and clean air laws, and private smoking bans in peoples' homes and places of work. Primary data collection was conducted by telephone but about $30 \%$ of interviews were conducted inperson in the household.

We limited the sample to women ages 18 and older. The sample of female self respondents ages 18 and older who report less than a completed high school education consisted of 75130 women from a total sample of 777713 .

\section{SES and other respondent characteristics}

In this study, educational achievement is the basis for selecting a sample of women of low SES. Osler $e t$ al theorise that education as a proxy for knowledge is not the sole pathway for better health outcomes; protective characteristics also may be derived from education as a proxy for ability to use knowledge and information, and education as a proxy for a broader SES in society and membership in social subcultures. We define low educational attainment as including up to and including some part of a 12th grade education but excluding attainment of a high school degree or GED*.

Other personal characteristics used in the model included race/ethnicity, age, marital status, and region of residence. Race/ethnicity was measured in five categories (white, black, Asian or Pacific Islander, Hispanic, Other). Age was measured as a dichotomous measure of young adults (ages 18-24) and adults (ages 25 and older). Marital status was distinguished by four separate variables for married or not married, which includes married (the reference group), single, widowed/divorced, separated and never married.

\section{Tobacco measures}

Individual respondents were first screened for tobacco use with an "ever use" screening measure. Respondents who reported that they had smoked at least 100 cigarettes in their lifetime were asked about their current smoking status. Current smokers were queried about the level of their current use in categorical terms (women who report now smoking every day or some days) and in continuous terms (number of cigarettes per day on average; number of days smoked out of past 30 days). All current smokers, regardless of the

${ }^{*}$ General educational development (GED) is a substitute for a high school diploma obtained through passing a test.

Table 1 Characteristics of the sample of low education* women, weighted, 1992-2002

\begin{tabular}{|c|c|c|c|c|}
\hline & $1992-93$ & $1995-96$ & $1998-99$ & 2001-02 \\
\hline Number & 228552 & 187141 & 176452 & 185568 \\
\hline \multicolumn{5}{|l|}{ Race/ethnicity† } \\
\hline White & $\begin{array}{l}60.0 \\
(59.2,60.7)\end{array}$ & $\begin{array}{l}57.5 \\
(56.7,58.3)\end{array}$ & $\begin{array}{l}55.4 \\
(54.5,56.2)\end{array}$ & $\begin{array}{l}52.0 \\
(51.0,52.9)\end{array}$ \\
\hline Black & $\begin{array}{l}19.1 \\
(18.5,19.7)\end{array}$ & $\begin{array}{l}16.8 \\
(16.2,17.4)\end{array}$ & $\begin{array}{l}16.5 \\
(15.8,17.2)\end{array}$ & $\begin{array}{l}16.2 \\
(15.5,16.9)\end{array}$ \\
\hline Asian or Pacific Islander & $\begin{array}{l}1.8 \\
(1.6,2.0)\end{array}$ & $\begin{array}{l}2.5 \\
(2.2,2.8)\end{array}$ & $\begin{array}{l}2.7 \\
(2.4,3.0)\end{array}$ & $\begin{array}{l}3.1 \\
(2.7,3.4)\end{array}$ \\
\hline Hispanic & $\begin{array}{l}18.4 \\
(17.8,19.0)\end{array}$ & $\begin{array}{l}21.9 \\
(21.2,22.6)\end{array}$ & $\begin{array}{l}24.3 \\
23.5,25.11\end{array}$ & $\begin{array}{l}27.5 \\
(26.6,28.4)\end{array}$ \\
\hline Other & $\begin{array}{l}0.8 \\
(0.7,0.9)\end{array}$ & $\begin{array}{l}1.4 \\
(1.2,1.6)\end{array}$ & $\begin{array}{l}1.2 \\
(1.0,1.4)\end{array}$ & $\begin{array}{l}1.3 \\
(1.1,1.5)\end{array}$ \\
\hline \multicolumn{5}{|l|}{ Age groups $\dagger$} \\
\hline $18-24$ & $\begin{array}{l}14.2 \\
(13.8,14.6)\end{array}$ & $\begin{array}{l}17.9 \\
(17.3,18.5)\end{array}$ & $\begin{array}{l}18.1 \\
(17.4,18.8)\end{array}$ & $\begin{array}{l}18.2 \\
(17.4,19.0)\end{array}$ \\
\hline $25+$ & $\begin{array}{l}85.8 \\
(85.4,86.3)\end{array}$ & $\begin{array}{l}82.2 \\
(81.5,82.8)\end{array}$ & $\begin{array}{l}81.9 \\
(81.2,82.6)\end{array}$ & $\begin{array}{l}81.8 \\
(81.0,82.7)\end{array}$ \\
\hline \multicolumn{5}{|l|}{ Marital statust } \\
\hline Married & $\begin{array}{l}59.7 \\
(59.5,60.0)\end{array}$ & $\begin{array}{l}58.4 \\
(58.1,58.6)\end{array}$ & $\begin{array}{l}56.8 \\
(56.5,5.57 .1)\end{array}$ & $\begin{array}{l}55.6 \\
(55.3,55.9)\end{array}$ \\
\hline Widowed/divorced & $\begin{array}{l}17.2 \\
(17.0,17.3)\end{array}$ & $\begin{array}{l}17.4 \\
(17.2,17.6)\end{array}$ & $\begin{array}{l}18.0 \\
(17.8,18.2)\end{array}$ & $\begin{array}{l}18.1 \\
(17.9,18.3)\end{array}$ \\
\hline Separated & $\begin{array}{l}2.8 \\
(2.7,2.8)\end{array}$ & $\begin{array}{l}2.8 \\
(2.7,2.9)\end{array}$ & $\begin{array}{l}2.6 \\
(2.5,2.7)\end{array}$ & $\begin{array}{l}2.4 \\
(2.4,2.5)\end{array}$ \\
\hline Never married & $\begin{array}{l}20.3 \\
(20.1,20.5)\end{array}$ & $\begin{array}{l}21.4 \\
(21.2,21.6)\end{array}$ & $\begin{array}{l}22.6 \\
(22.4,22.9)\end{array}$ & $\begin{array}{l}23.8 \\
(23.6,24.1)\end{array}$ \\
\hline \multicolumn{5}{|l|}{ Regiont } \\
\hline Northeast & $\begin{array}{l}18.6 \\
(18.1,19.1)\end{array}$ & $\begin{array}{l}18.5 \\
(17.9,19.1)\end{array}$ & $\begin{array}{l}18.9 \\
(18.2,19.5)\end{array}$ & $\begin{array}{l}18.2 \\
(17.5,18.9)\end{array}$ \\
\hline Midwest & $\begin{array}{l}20.8 \\
(20.2,21.4)\end{array}$ & $\begin{array}{l}20.0 \\
(19.4,20.7)\end{array}$ & $\begin{array}{l}19.5 \\
(18.8,20.2)\end{array}$ & $\begin{array}{l}18.6 \\
(17.9,19.3)\end{array}$ \\
\hline South & $\begin{array}{l}41.7 \\
(41.0,42.4)\end{array}$ & $\begin{array}{l}41.6 \\
(40.8,42.4)\end{array}$ & $\begin{array}{l}40.2 \\
(39.3,41.1)\end{array}$ & $\begin{array}{l}41.3 \\
(40.4,42.3)\end{array}$ \\
\hline West & $\begin{array}{l}19.0 \\
(18.4,19.6)\end{array}$ & $\begin{array}{l}19.8 \\
(19.1,20.5)\end{array}$ & $\begin{array}{l}21.5 \\
(20.7,22.2)\end{array}$ & $\begin{array}{l}21.9 \\
(21.1,22.7)\end{array}$ \\
\hline
\end{tabular}

*Low education category is women with education level "less than high school degree or GED". †Measured as a percentage of the sample with $95 \%$ confidence interval reported in parnetheses below. 
frequency or quantity defining their smoking behaviour, were included as eligible for this analysis.

\section{State level data: tobacco control policies}

Cigarette prices compiled by Orzechowski and Walker ${ }^{28}$ measured the average state level prices of cigarettes, including generics. We adjusted the price indices of the different waves for inflation using the consumer price index from the Bureau of Labor Statistics (BLS) (http:// www.bls.gov). We also adjusted for state tax changes and price changes at the national level (using the BLS cigarette price index) that occurred between sample months of the four waves. These data represent a snapshot of the state price and excise tax rate on a pack of cigarettes corresponding with the timing of each survey wave.

Clean air laws were represented by an index of state level clean air regulations informed by CDC, American Lung Association, and NCI data. ${ }^{29}$ We initially constructed separate variables for three types of laws: worksite, restaurant, and others (shopping malls, retail stores, enclosed arenas, and public transit). Based on studies of relative impact," states with "no smoking allowed (100\% smoke free)" were counted as $100 \%$ of the effect, with "no smoking allowed or designated smoking areas allowed if separately ventilated" as a 50\% effect, and with "designated smoking areas required or allowed" as a $25 \%$ effect. We used separate indices by type of law, and settled on an aggregate weighted index, with worksite laws weighted by $50 \%$, restaurant laws by $30 \%$, and laws for other public places by $20 \%$. Most of the developments in clean air regulations at the state level occurred after $2001 .{ }^{19}$

For media/comprehensive tobacco control campaigns at the state level, we developed an indicator variable. California and Massachusetts were the earliest states to institute comprehensive campaigns and are thus marked " $\mathrm{l}$ " for the full duration of the study period. Between 1994 and early 1999, Arizona and Oregon (started in 1995 and 1996 respectively), and Florida and Utah (1997) implemented campaigns. Between late 1999 and 2002, Hawaii, Indiana, Maine, Maryland, Minnesota, Mississippi, New Jersey, New York, Ohio, Vermont, Washington, and Wisconsin instituted programmes. We distinguished Florida, Mississippi, and Utah as having youth programmes rather than programmes targeted to the full population by assigning those states a value of 0.5 instead of 1.0. Programmes started in the earlier years have been described in the surgeon general's report
Reducing Tobacco Use. ${ }^{18}$ For more recent programmes, we considered information in Farrelly et $a^{32}$ and expenditures on tobacco control programmes available through CDC. We included states that spent more than $70 \%$ of the CDC goals in 2001 and 2002.

\section{Analysis}

Among women, two reference groups were defined by educational attainment: medium education women (high school degree or GED through an undergraduate college degree) and high education women (graduate level education). Low education men, under the same definition used for low education women, comprise a third reference group.

For the analyses, we use Stata 8.2 (StataCorp, 2003, College Station, TX) and individual weights to adjust for the survey design. We present individual level estimates of current smoking prevalence for four different subpopulations based on educational attainment and gender across the four survey waves of data. Logistic models of selected tobacco control policies on current smoking are estimated separately for each subpopulation, adjusting for personal characteristics. We focus our discussion on the models (by subpopulation) of stacked survey waves (all survey wave/years included) but also report where results from individual survey waves vary. The $95 \%$ confidence intervals of estimated odds ratios across subpopulations are compared.

\section{RESULTS}

\section{Sample characteristics}

The distribution of characteristics for the selected samples by education and gender are shown in table 1, over the course of the four survey waves. The proportion of white people among low education women fell from $60.0 \%(59.2 \%, 60.7 \%)$ to $52.0 \%(51.0 \%, 52.9 \%)$ over the study period, while the proportion of Hispanic women of low education increased from $18.4 \%(17.8 \%, 19.0 \%)$ to $27.5 \%(26.6 \%, 28.4 \%)$. The percentage of women ages $18-24$ increased from $14.2 \%$ $(13.8 \%, 14.6 \%)$ to $18.2 \%(17.4 \%, 19.0 \%)$. The percentage of married women decreased from $59.7 \%(59.5 \%, 60.0 \%)$ to $55.6 \%(55.3 \%, 55.9 \%)$, while the percentage of widowed/ divorced and never married increased to make up most of the gap.

\section{Smoking status}

Table 2 shows the smoking status of four subpopulations: low, medium, and high education female group, and low

Table 2 National estimates of current smoking prevalence, selected demographic groups, 1992-2002, weighted

\begin{tabular}{|c|c|c|c|c|c|}
\hline & & 1992-93 & $1995-96$ & 1998-99 & 2001-02 \\
\hline Total population & $\begin{array}{l}\text { Number } \\
\text { Percentage } \\
95 \% \mathrm{Cl}\end{array}$ & $\begin{array}{l}228552 \\
24.5 \\
(24.3,24.7)\end{array}$ & $\begin{array}{l}187141 \\
23.6 \\
(23.3,23.8)\end{array}$ & $\begin{array}{l}176452 \\
22.1 \\
(21.8,22.3)\end{array}$ & $\begin{array}{l}185568 \\
21.0 \\
(20.7,21.2)\end{array}$ \\
\hline Low education female* & & $\begin{array}{l}24456 \\
26.6 \\
(25.9,27.2)\end{array}$ & $\begin{array}{l}18988 \\
25.1 \\
(24.4,25.8)\end{array}$ & $\begin{array}{l}16185 \\
23.0 \\
(22.3,23.7)\end{array}$ & $\begin{array}{l}15501 \\
21.4 \\
(20.7,22.2)\end{array}$ \\
\hline Medium education female $†$ & & $\begin{array}{l}99085 \\
22.4 \\
(22.1,22.7)\end{array}$ & $\begin{array}{l}82742 \\
21.5 \\
(21.2,21.9)\end{array}$ & $\begin{array}{l}77675 \\
20.1 \\
(19.8,20.5)\end{array}$ & $\begin{array}{l}81179 \\
19.3 \\
(19.0,19.6)\end{array}$ \\
\hline High education female & & $\begin{array}{l}7187 \\
9.2 \\
(8.5,10.0)\end{array}$ & $\begin{array}{l}6390 \\
8.8 \\
(8.0,9.6)\end{array}$ & $\begin{array}{l}6773 \\
7.9 \\
(7.2,8.6)\end{array}$ & $\begin{array}{l}7733 \\
7.3 \\
(6.7,8.0)\end{array}$ \\
\hline Low education male* & & $\begin{array}{l}17474 \\
35.1 \\
(34.3,35.9)\end{array}$ & $\begin{array}{l}13102 \\
33.9 \\
(33.0,34.9)\end{array}$ & $\begin{array}{l}11830 \\
31.8 \\
(30.9,32.8)\end{array}$ & $\begin{array}{l}12244 \\
30.4 \\
(29.5,31.4)\end{array}$ \\
\hline
\end{tabular}

*Low education female/male category is women/men with education level more than high school degree or GED. †Medium education female category is women with education level more than high school degree or GED and less than or equal to bachelors degree. fHigh education female category is women with education level more than bachelors degree. 
education male group. Among these subpopulations, the low education male group report the highest estimated current smoking prevalence throughout the study period, followed by the low education female group. Compared with the total population, current smoking prevalence among the low education female group exceeded national estimates in the earlier years of the study period but has moved closer to the estimated smoking prevalence of the total population in later years. In 1992/93, the estimated prevalence among the low education female group was $26.6 \%(25.9 \%, 27.2 \%)$ and in the total population was $24.5 \%(24.3 \%, 24.7 \%)$. By $2001-02$, prevalence among the low education female group was $21.4 \%$ $(20.7 \%, 22.2 \%)$ and in the total population was $21.0 \%(20.7 \%$, $21.2 \%)$. The estimated prevalence for each of the subpopulations differs statistically from the others over time, and the estimated prevalence among the female samples is substantially lower for those with greater reported education.

In keeping with the overall decline in smoking prevalence at the national level over the period, the estimated prevalence of smoking in each of the selected subpopulations is significantly lower in 2001-02 than in 1992-93. The greatest declines, however, are for the low education samples, both female and male. The smoking rate declined 5.2 percentage points among the low education female sample from $26.6 \%$ $(25.9 \%, 27.2 \%)$ in $1992-93$ to $21.4 \%(20.7 \%, 22.2 \%)$ in $2001-$ 02 . The percentage point decline in smoking among the low education male sample was $4.7 \%$, similar in absolute terms but lower in relative terms because of the higher initial smoking rates $(35.1 \%)$. Smaller reductions are seen for higher education female groups $3.1 \%$ in absolute terms for medium education, $1.9 \%$ for high education), although both of these groups, especially the high education female group, had lower smoking rates to begin with (9.2\% in 1992-93).

\section{Logistic models of current smoking}

The following sections describe the results of multiple logistic models with classifications by education, as shown in table 3 . In each model, we controlled for age, race/ethnicity, individual marital status, and geographical residence. By race/ethnicity, we found that smoking was highest among the white population and Others (mostly American Indian) for all groups except the high education female group.
Among the comparison populations, higher smoking rates are uniformly estimated for all single (never married, separated, and divorced/widowed) persons than for married persons. This uniformity is not seen among low education female sample, among whom the widowed/divorced have a lower odds of current smoking than the married. For low education women, smoking rates were higher among all areas outside the northeast region of the USA.

\section{Cigarette price and current smoking}

Over the period 1992-2002, the likelihood of a low education woman being a current smoker decreased with higher cigarette prices (odds ratio $=0.74 ; 95 \%$ CI: 0.62, 0.89). The odds ratio of 0.74 produces a price elasticity near one, implying that a $10 \%$ increase in price would reduce smoking by $10 \%$. This estimate falls in the same range as the parallel odds ratios for the low education male sample $(\mathrm{OR}=0.70$; $0.58,0.85)$ and for medium education female sample $(\mathrm{OR}=0.83 ; 0.76,0.90)$. In the stacked model, the price effect for high education female sample is not significant.

Models of separate survey waves show some fluctuation in the role of price over time for these selected subpopulations. Over time, the odds ratio for price on current smoking is less than one for low education female sample in 1992-93 and 2001-02, but insignificant in the intervening survey waves although still negative and falling within overlapping confidence intervals over the full period. The likelihood of smoking given increasing price is negative for the low education male sample in each survey wave except 199899, and the confidence interval for the 1998-99 estimate overlaps those of the other survey waves. Women with more than a high school education seem less responsive to price. For the medium education female sample, the odds ratio is less than one only in 2001-02, and the estimates for previous survey waves are statistically different from the 2001-02 estimate based on an examination of the confidence intervals. The odds ratios for the high education female sample are insignificant, with broad confidence intervals. These price results were consistent with and without the clean air and media variables included in the models.

Based on guidance from the literature, we examined two interaction models for the low education female sample. In

Table 3 Logistic regression analysis of smoking status, populations aged 18 years or older, 1992-2002

\begin{tabular}{|c|c|c|c|c|c|c|c|c|c|c|c|c|}
\hline & \multicolumn{3}{|c|}{ Low education women } & \multicolumn{3}{|c|}{ Low education men } & \multicolumn{3}{|c|}{ Medium education women } & \multicolumn{3}{|c|}{ High education women } \\
\hline & \multicolumn{2}{|l|}{ Odds ratio } & $95 \% \mathrm{Cl}$ & \multirow[t]{2}{*}{ Odds ratio } & \multicolumn{2}{|r|}{$95 \% \mathrm{Cl}$} & \multicolumn{2}{|l|}{ Odds ratio } & \multirow[t]{2}{*}{$95 \% \mathrm{Cl}$} & \multicolumn{2}{|c|}{ Odds ratio } & $95 \% \mathrm{Cl}$ \\
\hline \multicolumn{11}{|l|}{ Age (ref: 18-24 years) } & & \\
\hline $25+$ years & 0.97 & 0.90 & 1.04 & $1.17^{\star}$ & 1.08 & 1.26 & 1.01 & 0.97 & 1.05 & 1.35 & 0.77 & 2.38 \\
\hline \multicolumn{13}{|c|}{ Race/ethnicity (ref: White) } \\
\hline Black & $0.63^{*}$ & 0.59 & 0.67 & $0.80^{*}$ & 0.75 & 0.86 & $0.70^{*}$ & 0.68 & 0.73 & 1.02 & 0.84 & 1.23 \\
\hline Asian or Pacific Islander & $0.19^{*}$ & 0.15 & 0.24 & $0.69^{*}$ & 0.58 & 0.82 & $0.37^{*}$ & 0.34 & 0.40 & $0.52^{*}$ & 0.38 & 0.73 \\
\hline Hispanic & $0.27^{*}$ & 0.25 & 0.29 & $0.61^{*}$ & 0.57 & 0.65 & $0.53^{*}$ & 0.50 & 0.56 & 0.93 & 0.69 & 1.26 \\
\hline Other & $1.28^{*}$ & 1.08 & 1.51 & $1.57^{*}$ & 1.30 & 1.88 & $1.62^{*}$ & 1.47 & 1.79 & 1.52 & 0.84 & 2.74 \\
\hline \multicolumn{13}{|c|}{ Marriage status (ref Married) } \\
\hline Widowed/divorced & $0.77^{*}$ & 0.74 & 0.81 & $1.35^{\star}$ & 1.28 & 1.43 & $1.63^{*}$ & 1.60 & 1.67 & $2.19^{*}$ & 1.95 & 2.47 \\
\hline Separated & $2.39^{*}$ & 2.19 & 2.60 & $2.41^{*}$ & 2.13 & 2.71 & $2.92^{*}$ & 2.77 & 3.08 & $2.18^{*}$ & 1.55 & 3.07 \\
\hline Never married & $1.53^{*}$ & 1.43 & 1.63 & $1.58^{*}$ & 1.47 & 1.68 & $1.60^{*}$ & 1.55 & 1.65 & $1.92^{*}$ & 1.69 & 2.17 \\
\hline \multicolumn{13}{|l|}{ Region (ref: Northeast) } \\
\hline Midwest & $1.18^{*}$ & 1.11 & 1.25 & $1.17^{*}$ & 1.09 & 1.25 & $1.07^{*}$ & 1.04 & 1.10 & 1.04 & 0.91 & 1.20 \\
\hline South & $1.16^{*}$ & 1.09 & 1.23 & $1.19^{*}$ & 1.12 & 1.27 & 0.99 & 0.96 & 1.02 & 1.07 & 0.93 & 1.24 \\
\hline West & $1.26^{*}$ & 1.17 & 1.37 & 1.08 & 1.00 & 1.17 & $0.94^{*}$ & 0.90 & 0.97 & 0.95 & 0.80 & 1.12 \\
\hline \multicolumn{13}{|l|}{ Year (ref: 1993) } \\
\hline 1996 & $0.92^{*}$ & 0.87 & 0.97 & $0.93^{*}$ & 0.87 & 0.98 & $0.94^{*}$ & 0.92 & 0.97 & 1.00 & 0.87 & 1.15 \\
\hline 1999 & $0.91^{*}$ & 0.86 & 0.97 & $0.94^{*}$ & 0.88 & 1.00 & $0.92^{*}$ & 0.90 & 0.95 & $0.85^{*}$ & 0.73 & 0.99 \\
\hline 2002 & 0.95 & 0.87 & 1.04 & 0.97 & 0.88 & 1.06 & $0.94^{*}$ & 0.90 & 0.98 & $0.76^{*}$ & 0.61 & 0.94 \\
\hline \multicolumn{13}{|l|}{ Policies } \\
\hline Log (Price) & $0.74^{*}$ & 0.62 & 0.89 & $0.70^{*}$ & 0.58 & 0.85 & $0.83^{*}$ & 0.76 & 0.90 & 1.21 & 0.79 & 1.85 \\
\hline Media & $0.86^{*}$ & 0.82 & 0.96 & $0.92^{*}$ & 0.86 & 1.00 & $0.89^{*}$ & 0.86 & 0.92 & 0.93 & 0.79 & 1.09 \\
\hline Clean air & 0.91 & 0.80 & 1.03 & 0.96 & 0.84 & 1.09 & $0.88^{*}$ & 0.83 & 0.94 & 0.83 & 0.61 & 1.13 \\
\hline
\end{tabular}


contrast with expectations, we found no interaction between age and price in this population. However, an interaction for race/ethnicity and cigarette price does appear over the study period. Overall, within the low education female population, we find that African-Americans and those not falling into a named category of race/ethnicity (that is, persons marked "Other," mostly American Indian and Eskimo) seem to be less responsive than the white population to price in terms of modifying their smoking status. By contrast, Asian-American and Hispanic women of low reported education seem to have been more responsive to price than white female subpopulation.

\section{Media and current smoking}

Media/comprehensive state campaigns seem to be similar and significant for the low and medium education female samples in the stacked models over the full study period. The likelihood of being a current smoker in a state with a tobacco control media campaign was $14 \%$ lower $(\mathrm{OR}=0.86 ; 0.82$, $0.96)$ for low education female sample, $8 \%$ lower $(\mathrm{OR}=0.92$; $0.85,1.00)$ for low education male sample, and $11 \%$ lower for $(\mathrm{OR}=0.89 ; 0.86,0.92)$ for medium education female group. An overall effect of media does not appear for the high education female sample.

In individual survey waves, these results vary somewhat. The association between media and current smoking among low education women appears in 1992-93 and 1995-96 but disappears in subsequent survey waves. Among the medium education female sample, the role of media is consistent until the 2001-02 survey wave. In 1995-96, an odds ratio similar to the reported levels of other groups is estimated for the low income male sample, but the effect is otherwise insignificant in this group. Generally, the association of the media variable and smoking prevalence declines in the more recent survey waves.

\section{Clean air laws and current smoking}

Over the period 1992-2002, current smoking among low education women is inversely related to the index of clean air laws with an odds ratio of $0.91(0.80,1.03)$, but is significant only in the medium education female subpopulation, with an odds ratio of $0.88(0.83,0.94)$. These results are borne out by the single survey wave models for each of the other subpopulations. However, only in the 2001/02 model do clean air laws seem to play a part for the medium education female sample, although the confidence intervals around the estimates for each survey wave overlap for this group.

\section{DISCUSSION}

Nationally representative estimates of current smoking in four selected subpopulations defined by gender and level of attained education show that smoking prevalence varies across groups and the decline in smoking prevalence was greater for some than others. Women and men of low education report overall higher rates of smoking but also greater declines in smoking prevalence over the period 1992 2002. Interestingly, among the low education female sample over the 1992-2002 period, separated and never married women had higher rates of smoking than married women while divorced/widowed had lower rates, a pattern not found among the comparison groups for whom all single persons had higher rates of smoking than married persons. Speculatively, this could showe an economic constraint among divorced and widowed low education women.

The 1992-2002 pattern of a greater decline among women with less education contrasts with data reported for an earlier period. Between 1974 and 1990, the annual decline in smoking prevalence among women was about $4 \%$ for those with college degrees and $2.2 \%$ or less for women with less than a college degree. ${ }^{7}$ Although the association with education did not appear in the data for 1990-1995, the 1995 rate of smoking for women with less education was 2.4 times the rate of women with more education while the 1974 differential was narrower (1.4). With the expansion of tobacco control policy efforts in the 1990s, both in variety and in intensity, it is not surprising that trends in different subpopulations might change. In particular, prices increased substantially between 1997 and 2002, the period over which we see the largest declines in prevalence.

Low education women seem particularly responsive to price and media tobacco control efforts. The price of cigarettes seems to play a bigger part in current smoking behaviour for both low education women and men, compared with more highly educated women. This is consistent with other analyses showing a greater price effect for people of lower SES. Over the period 1976-1993, using data from the national health interview survey (NHIS), people of lower income were more likely to change their smoking behaviour in response to price increases than were respondents reporting higher incomes. ${ }^{33}$ Tax increases can play an important part in reducing smoking rates among low SES women.

State media/comprehensive campaigns were associated with current smoking behaviour among low and medium education women, but not among women with more than a college education. The role of media may be dissipating over time, perhaps because of a saturation effect from national tobacco control news that may supersede campaigns run at the state level or because more recent campaigns have been less intense than in earlier years. By 2001-2002, the truth campaign was being aired nationally, and secondarily targets 18-24 year olds. To capture this phenomenon, we included a variable interacting the 2001-02 sample with an indicator for 18-24 year olds. The odds ratio was less than one as expected, but insignificant for both the female and male low education samples. Better measures that distinguish the role of media campaigns from other tobacco control programmes and that show campaign intensity (for example, per capita expenditures) and duration may help to improve the ability to distinguish state programme effects. Nevertheless, the results suggest an important role for media campaigns.

The index of clean air laws used in our analyses suggests at most a marginal effect on current smoking. When we added separate variables for restaurant clean air laws and worksite laws, we continued to get weak results. However, when we included a variable from the TUS-CPS marking indoor workers who were subject to a smoking ban, we found that this variable showed significant negative effects for each of the subpopulations studied, except high income women. The lack of stronger effects for the state level clean air index for low education populations may reflect that they are probably less likely to be subject to private worksite smoking bans. Generally, more refined measures of clean air laws that measure local policy variations and enforcement would yield more precise results.

Particularly for low SES populations, another set of policy variables not included in this study warrants closer attention. Data now exist on which cessation services are covered by Medicaid. A report of the various forms of medication and counselling covered by Medicaid notes the disproportionately high smoking prevalence in the population receiving Medicaid coverage. ${ }^{34}$ Our preliminary analyses in this area yielded challenges with the collinearity of state policy variables, and further work is required.

Race/ethnicity is an important characteristic in modelling smoking behaviour as shown in our analyses and reported elsewhere. ${ }^{15}$ We note that categorisation of people into five groups can mask more detail. For example, examining 
Asian-Americans as a group masks different rates of smoking for people from different Asian cultures. ${ }^{35}$ The difference in black-white health outcomes is at least partially accounted for by income differentials, although race does have an effect independent of income, with black-white differentials in health outcome at every level of income. ${ }^{36}$ Scarinci et al ${ }^{9}$ note that the interaction between income and ethnicity is important to examine, and other analyses show a relation between race/ethnicity and price..$^{33}$ Looking at cigarette price as the key tobacco control policy theoretically related to income, in preliminary analyses we examined the interaction of race/ethnicity and cigarette price in our low education female sample. We found a consistent trend for AfricanAmericans to be less responsive to price than the white population, although some evidence ${ }^{33}$ suggests that AsianAmericans and Hispanics are more responsive to price than the white population. Further work is needed in this area.

In addition to our individual level analysis, we conducted preliminary analyses of the role of tobacco control policies and prevalence of smoking among low education women aggregated to the state level. We also examined the percentage and absolute change in policy values and smoking prevalence between survey years. Overall, these preliminary efforts did not yield significant results for the role of policies, but we would note that the smoking rates at the state level fluctuate substantially from survey wave to survey wave. Small sample sizes at the state level for the population of interest may be introducing a considerable degree of error. Further examination of the data at the state level is warranted.

To gauge more precisely how policies affect smoking rates over time, further analysis might also consider the effect of policies on quantity smoked and cessation. Our preliminary analysis found that the likelihood of being a someday rather than every day smoker was greater for low education men and women and medium education women in states with higher prices. Among every day smokers, the quantity smoked by low education the male and female and medium education female samples was found to be lower in states with stricter clean air laws. Higher prices were also associated with reduced quantity smoked by low education male sample and medium education female sample, but the association was insignificant among the low education female sample.

These analyses may be affected by the way that we specified SES status in terms of education. Multiple characteristics or vectors to represent SES may be preferable. ${ }^{87}$ Sample selection for our analyses was originally based on education and income characteristics. Because women with minimal education seem to have improved their financial lot over time, combining these two characteristics in an index was not tenable. Because of the higher proportion of respondents with missing data in household income and problems with the measurement of income in the TUS-CPS sample, we chose to focus on the education samples. In models not reported here, we included a control for whether the respondent was also from a low income household (lowest quintile) to control for income within the low

\section{What is known on this subject}

Women with less than a high school education are three times more likely to be current smokers than women with a college education. Some studies of female smoking have examined SES and some studies of tobacco control policies have looked at the impact on women and those of lower SES. Further study is needed, especially regarding women and low SES in conjunction.

\section{What this paper adds}

Using a 10 year span of nationally representative data, we examine the role of tobacco control policies associated with smoking among women of low SES. We describe the prevalence of smoking in the selected population, comparing these data to three reference groups-women of two different higher SES groups and men of low SES- and we assess whether tobacco control policies have a differential effect on the selected population compared with the three reference groups.

education group, and obtained very similar results to the models reported above. Preliminary investigation using household income to define our samples also yielded similar results, but was subject to limitations of the TUS-CPS data in distinguishing income beyond preset categories (as specified in the original data).

A potential concern is that variables that are correlated with lower SES may be omitted in our models. For example, childhood SES may be a more important determinant of adult smoking than own SES in adulthood. ${ }^{6}$ Kiefe et $a l^{38}$ found that barriers to accessing health services (for example, no health insurance) were associated with higher rates of smoking initiation, higher prevalence of smoking, and lower rates of cessation, even controlling for four measures of SES (education, family income, unemployment, and marital status). Fagan et $a l^{35}$ make the point that in an epidemiological study looking at socioeconomic differences, it would be useful to operationalise a measure of individual stress. Personal occupation as a measure of SES has also been found to play an independent part in smoking status. ${ }^{8}$

Contextual characteristics, such as neighbourhood residence, may be important as well. ${ }^{10}$ For example, the degree of material deprivation in a respondent's residential area has been found to be related to current smoking status independently of respondent education and social class. ${ }^{11}$ Williams et $a l^{36}$ find effects of neighbourhood residence, biases in medical care, and life stress resulting from discrimination separate from SES impact on health outcomes. Without a contextual component, analyses at the individual level may miss broader environmental contributions to smoking behaviour and differences across groups. ${ }^{35}$ One option is to specify measures of education and income aggregated at the postcode (zip code) level, as this approach may capture some community level characteristics that were omitted in our analyses.?

Finally, the results are cross sectional and are subject to bias from omitted variables. In particular, those states with strong antismoking sentiments may implement stricter policies, and these sentiments may be the underlying reason for low smoking rates. When we included separate indicator variables for each state to account for state characteristics otherwise not measured (such as the normative antismoking environment), there was a swamping of most of the policy variable effects in the stacked model over the study period 1992-2002. Consequently, state fixed effects were omitted from the model results that we report. However, further attention is merited.

In summary, using nationally representative data, we found that declining trends in smoking over the period 1992-2002 appeared in each of our selected education samples, but that greater relative declines occurred for low education populations. Moreover, evidence showed that compared with better educated women, low education women responded with greater positive effect to certain policy measures, particularly price. Media campaigns also 
were found to be effective. Campaigns targeted to low SES populations may prove even more effective in reducing smoking rates than the general campaigns found in this study. Furthermore, among women who have not completed high school, price plays a different part for different racial/ ethnic groups. With higher smoking rates among low education women and the corollary of increased risks of morbidity and mortality, targeting effective policy measures for this group should be a public health mandate. On a positive note, the association between SES and smoking behaviour is not immutable. It does not appear in cohorts born before 1930 (that is, people 75+ years old at this point) despite the strong association in later cohorts. ${ }^{8}$ By helping to counter targeted marketing strategies, personal stressors, and debilitating neighbourhood characteristics, the public health community may make strides in narrowing the SES related smoking gap to the benefit of all.

\section{ACKNOWLEDGEMENTS}

The authors are grateful to the organisers of "Tobacco Control Policies: Do They Make a Difference for Low SES Women and Girls?" for their inspiration for this paper and to conference participants for their comments on the original presentation.

\section{Authors' affiliations}

D T Levy, Pacific Institute for Research and Evaluation, Calverton, USA; University of Baltimore, USA

E A Mumford, C Compton, Pacific Institute for Research and Evaluation

Funding: support for this paper was partially provided by grant number UO1-CA-097450 of the National Cancer Institute's CISNET Program and by grant number R03 DA17942-01 from the National Institute on Drug Abuse.

Conflicts of interest: DTL and CMC have no competing interests to declare. EAM has a financial interest in a venture to develop a new nicotine replacement product.

\section{REFERENCES}

1 Doll R, Peto R, Boreham J, et al. Mortality in relation to smoking: 50 years' observations on male British doctors. BMJ 2004;328:1519.

2 Institute of Medicine. Unequal treatment: confronting racial and ethnic disparities in health care. Washington, DC: National Academy Press, 2002.

3 Williams DR, Jackson PB. Social sources of racial disparities in health. Health Aff (Millwood) 2005; 24:325-34.

4 Kawachi I, Daniels N, Robinson DE. Health disparities by race and class: why both matter. Health Aff (Millwood) 2005;24:343-52.

5 Flint AJ, Novotny TE. Poverty status and cigarette smoking prevalence and cessation in the United States, 1983-1993: the independent risk of being poor. Tob Control 1997:6:14-18.

6 Gilman SE, Abrams DB, Buka SL. Socioeconomic status over the life course and stages of cigarette use: initiation, regular use, and cessation. J Epidemiol Community Health 2003;57:802-8.

7 Pamuk E, Makuc D, Heck K, et al. Socioeconomic status and health chartbook. Health, United States, 1998. Hyattsville, MD: National Center for Health Statistics, 1998

8 Osler M, Holstein B, Avlund K, et al. Socioeconomic position and smoking behaviour in Danish adults. Scand J Public Health 2001;29:32-9.

9 Scarinci IC, Robinson LA, Alfano CM, et al. The relationship between socioeconomic status, ethnicity, and cigarette smoking in urban adolescents. Prev Med 2002;34:171-8.

10 Shenassa ED, McCaffery JM, Swan GE, et al. Intergenerational transmission of tobacco use and dependence: a transdisciplinary perspective. Nicotine Tob Res 2003;5(suppl 1):S55-69.

11 Shohaimi S, Luben R, Wareham N, et al. Residential area deprivation predicts smoking habit independently of individual educational level and occupational social class. A cross sectional study in the Norfolk cohort of the European Investigation into Cancer (EPIC-Norfolk). J Epidemiol Community Health 2003;57:270-6.

12 Burns D, Anderson C, Johnson M, et al. Cessation and cessation measures among daily adult smokers: national- and state-specific data. Populationbased smoking cessation: a conference on what works to influence smoking in the general population. Smoking and tobacco control monograph no 12.
Bethesda, MD: National Cancer Institute, National Institutes of Health, 2000: 113-304.

13 Levy DT, Romano E, Mumford E. The relationship of smoking cessation to sociodemographic characteristics, smoking intensity, and tobacco control policies. Nicotine Tob Res 2005;7:387-96.

14 US Department of Health and Human Services. Women and smoking: a report of the surgeon general. Rockville, MD: Centers for Disease Control and Prevention, National Center for Chronic Disease Prevention and Health Promotion, Office on Smoking and Health, 2001.

15 US Department of Health and Human Services. Tobacco use among US racial/ethnic minority groups: a report of the surgeon general. Atlanta, GA: Centers for Disease Control and Prevention, National Center for Chronic Disease Prevention and Health Promotion, Office on Smoking and Health, 1998.

16 Lynch JW, Kaplan GA, Pamuk ER, et al. Income inequality and mortality in metropolitan areas of the United States. Am J Public Health 1998;88:1074-80.

17 Lynch J, Harper S, Kaplan GA, et al. Associations between income inequality and mortality among US states: the importance of time period and source of income data. Am J Public Health 2005;95:1424-30.

18 US Department of Health and Human Services. Reducing tobacco use: a report of the surgeon general. Atlanta, GA: Centers for Disease Control and Prevention, National Center for Chronic Disease Prevention and Health Promotion, Office on Smoking and Health, 2000.

19 Levy DT, Nikolayev L, Mumford E. Recent trends in smoking and the role of public policies: results from the SimSmoke tobacco control policy simulation model. Addiction 2005;100:1526-36.

20 Centers for Disease Control and Prevention. http://www.cdc.gov/nchs/ data/nhis/earlyrelease/200506_08.pdf.

21 California Tobacco Education, Research Oversight Committee (TEROC). Toward a tobacco-free California 2003-2005: the myth of victory. Master plan of the California Tobacco Education and Research Oversight Committee. http://www.dhs.ca.gov/tobacco/documents/TobaccoMasterPlan2003.pdf, 2003.

22 US Department of Health and Human Services. Healthy people 2010. Atlanta: Centers for Disease Control, Office of Disease Prevention and Health Promotion, 2000.

23 Levy DT, Cummings KM, Hyland A. Increasing taxes as a strategy to reduce cigarette use and deaths: results of a simulation model. Prev Med 2000;31:279-86.

24 World Health Organisation. Guidelines for controlling and monitoring the tobacco epidemic. Geneva: World Health Organisation, 1998.

25 Townsend J. Cigarette tax, economic welfare and social class patterns of smoking. Applied Economics 1987; 19:355-65.

26 Ohsfeldt R, Boyle R, Capilouto E. Tobacco taxes, smoking restrictions, and tobacco use. Cambridge, MA National Bureau of Economic Research, 1998.

27 Farrelly MC, Evans WN, Sfekas AE. The impact of workplace smoking bans: results from a national survey. Tob Control 1999;8:272-7.

28 Orzechowski W, Walker RC. The tax burden on tobacco: historical compilation, Vol 37. Arlington, VA: Orzechowski and Walker, 2002.

29 Levy DT, Friend K, Polishchuk E. Effect of clean indoor air laws on smokers: the clean air module of the SimSmoke computer simulation model. Tob Control $2001 ; 10: 345-51$.

30 National Cancer Institute. State and local legislative action to reduce tobacco use. Bethesda, MD: US Department of Health and Human Services, National Institutes of Health, National Cancer Institute, 2000.

31 Levy DT, Friend KB. The effects of clean indoor air laws: what do we know and what do we need to know? Health Educ Res 2003;18:592-609.

32 Farrelly MC, Healton CG, Davis KC, et al. Getting to the truth: evaluating national tobacco countermarketing campaigns. Am J Public Health 2002;92:901-7.

33 Farrelly M, Bray J. Response to increases in cigarette prices by race/ethnicity, income, and age groups-United States, 1976-1993. MMWR Morb Mortal Wkly Rep 1998;47:605-9.

34 Halpin H, McMenamin S, Keeler C, et al. State Medicaid coverage for tobacco-dependence treatments - United States, 1994-2002. MMWR Morb Mortal Wkly Rep 2004;53:54-7.

35 Fagan P, King G, Lawrence D, et al. Eliminating tobacco-related health disparities: directions for future research. Am J Public Health 2004;94:211-17.

36 Williams DR. Race, socioeconomic status, and health. The added effects of racism and discrimination. Ann N Y Acad Sci 1999;896:173-88.

37 Centers for Disease Control and Prevention. Eliminating health disparities. Public health puzzle: social determinants of health, Chronic Disease Notes and Reports, 2002;15.http://www.cdc.gov/nccdphp/cdnr/ cdnr_spring0201.htm.

38 Kiefe CI, Williams OD, Greenlund KJ, et al. Health care access and seven year change in cigarette smoking. The CARDIA study. Am J Prev Med 1998; 15: 146-54.

39 Novak SP, Reardon SF, Buka SL. How beliefs about substance use differ by socio-demographic characteristics, individual experiences, and neighborhood environments among urban adolescents. J Drug Educ 2002;32:319-42. 